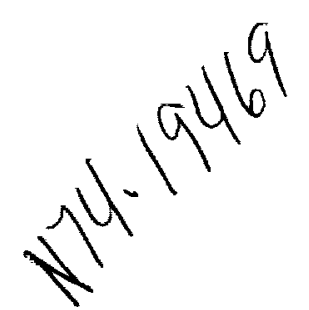

\title{
33. On the Primordial Condensation and Accretion Environment and the Remanent Magnetization of Meteorites
}

\author{
Aviva Brecher \\ University of California, San Diego \\ La Jolla, California
}

\begin{abstract}
Attention is drawn to the fact that neither astronomical observations, nor laboratory data can, as yet, sufficiently constrain models of the origin and evolution of the solar system. But, if correctly approached and interpreted, the magnetic remanence of meteorites could help in constructing a self-consistent model.

In the context of various models for the early evolution of a solar nebula, the possible roles assigned to ambient magnetic fields and the paleointensities required to establish the stable natural remanent magnetization (NRM in range $10^{-4}$ to $10^{-1} \mathrm{cgsm}$ ) observed in meteorites, are discussed. It is suggested that the record of paleofields present during condensation, growth, and accumulation of grains is likely to have been preserved as chemical (CRM) or thermochemical (TCRM) remanence in unaltered meteoritic material. This interpretation of the meteoritic NRM is made plausible by experimental and theoretical results from the contiguous fields of rock magnetism, magnetic materials, interstellar grains, etc. Several arguments (such as the anisotropy of susceptibility in chondrites, suggesting alignment of elongated ferromagnetic grains, or the characteristic sizes and morphology of carrier phases of remanence, etc.) as well as general evidence from meteoritics (cooling rates, chemical and mineralogical data) can be used to challenge the interpretation of NRM as thermo-remanence (TRM) acquired on a "planetary" parent body during cooling of magnetic mineral phases through the Curie point in fields of 0.2 to $0.9 \mathrm{Oe}$.

Fine-particle theories appear adequate for trealing meteoritic remanence, if models based on corresponding types of permanenl magnet materials, e.g., powder-ferrites for chondrites; diffusion hardened alloys for iron meteorites, are adopted, as suggested here.

Finally, a potentially fruitful sequence of experiments is suggested for separating the useful component of NRM in determining the paleofield intensity and its time evolution.
\end{abstract}

TT HAS BECOME APPARENT IN RECENT YEARS that 1 the record of the physico-chemical condensation environment in the circumsolar region may have been at least partly preserved in meteorites. (See Anders, 1971a, for an up-to-date review.)

Recent systematic attempts to use the chemical evidence derived from the study of meteorites in order to constrain models of the origin and evolution of the solar system material have led to the emergence of several alternative interpretations of the same body of chemical and mineralogical evidence. If indeed, as is widely held, meteorites 
originated in several small, asteroidal (Levin, 1969; Anders, 1971b) or cometary (Öpik, 1968; Wetherill, 1971) bodies, which accreted (Alfvén and Arrhenius, 1970) in the region between the terrestrial and the giant planets ( 2 to $5 \mathrm{AU}$ ) or beyond, they should reflect this transition zone paleo-environment. The wide spectrum of physical and chemical properties, from the dense $(\rho \sim 8$ $\left.\mathrm{g} / \mathrm{cm}^{3}\right)$, coarsely crystalline and chemically reduced iron meteorites to the fluffy $\left(\rho \sim 2 \mathrm{~g} / \mathrm{cm}^{3}\right)$, more oxidized and fine-grained disordered phases of carbonaccous chondrites (Kerridge, 1967), must be explained by a single parametrized model of condensation and accretion. In Section 1, some aspects of the condensation of solid grains in several representative models will be high-lighted. The characteristic size and composition spectrum of unaltered grains in meteorites appears not to be incompatible with most models. Moreover, it appears that astronomical observations of circumstellar condensation, or available laboratory data cannot, at this stage, help rule out or drastically constrain these models. In Section 2, the interaction of magnetic fields in space with the grains, as well as their rolc in fractionation and aggregation processes in the solar system, will be discussed. The duration and importance of the grain stage in the preaggregation lifetime of meteoritic material, and the likelihood of grains having acquired early a stable chemical remanent magnetization (CRM), if growing in magnetic fields, will be discussed. In Section 3, the possible evidence for the presence of a magnetic field during grain growth and agglomeration, as expressed in the shape anisotropy and apparent alignment of magnetic grains in chondrites, will be reviewed, and placed into the framework of the natural remanent magnetization (NRM) of meteorites, tektites and lunar materials. It can be expected that the stable natural remanent magnetization found in all the types of metcorites will provide information on the ambient magnetic fields in the circumsolar region at the time of condensation and agglomeration of grains into solid bodies. The possible origins, modes of acquisition, and carrier phases of this fossil magnetism will also be discussed in the context of relevant data from rockmagnetism and magnetic matcrials, in Section 3.

The importance of meteoritic palcomagnetism in further constraining theories of primordial condensation might be decisive, if integrated with the chemical, mineralogical and thermal history picture for various classes of meteorites. Therefore, in Section 4 an experimental approach for selecting the useful components of NRM and its carricr phases, and retrieving information on the palcointensity, will be outlined. Several potentially useful directions for future experimental and theoretical research in meteoritic magnetism will be indicated and tests of consistency with extant theories will be sketchily described.

\section{CONDENSATION MODELS AND OBSER VED PROPERTIES OF COSMIC GRAINS}

Among the several condensation models attempting to account for chemical fractionation patterns in meteoritic material are those of Larimer and Anders (1967) and Larimer (1970) based on molecular equilibria in the "cosmic" gas, be it rapidly or slowly cooled; of Blander and Katz (1967) and Blander and Abdel-Gawad (1969), in which nucleation of solid grains is retarded until the cooling gas has become supersaturated; or of Arrhenius and Alfvén (1971), where condensation proceeds at manifest thermochemical non-equilibrium as "cool" grains grow in a "hot" plasma-gas medium. These models must (partially) overlap with theories which approached the problem of planetary cosmogony from the physical-dynamical point of view, attempting to explain mostly the observed, largescale, rather than fine structure, fractionation in the solar system. Examples are the magnetohydrodynamical models (Alfvén, 1954; Hoyle, 1963) in which the magnetic fields required to arrive at the observed angular momentum distribution in the solar system, could also afford chemical fractionation in an ionization-controlled sequence of condensation of elements (Jokipii, 1964; Arrhenius and Alfvén, 1971). In a hydrodynamical model proposed by Cameron (1969, 1973) no magnetic fields are explicitly considered, the observed chemical and dynamical features being attributed to gravitational settling and thermally driven convection and turbulence in a solar nebula. Pressure and temperature parameters borrowed from this model were incorporated into the "chemical" model of Larimer and Anders (1967) and Larimer (1970). 


\section{Astronomical Observations}

To what extent could astronomical observations of circumstellar gas-dust envelopes be used to further select between these models? Recent infrarcd observations of young T-Tauri stars like R-Monocerotis (which, having spectral type G and close to solar mass, is similar to our Sun), or of later-type cool stars like T-Tauri (K-type) or VY Canis Majoris (M-type) (Low and Smith, 1966; Low et al., 1970; Herbig, 1970), revealed the presence of envelopes of dust at temperatures of 500 to $900^{\circ} \mathrm{K}$, in which grain sizes of submicron and a few microns appear to be present. Such objects have been tentatively interpreted as preplanetary systems, and parameters such as temperature and molecular distributions for a disk-nebula model (Herbig, 1970) appeared to be in rcasonable agreement with those expected for a solar nebula in most models. The rapid mass loss rates ( $\lesssim 10^{-7} M_{\odot} / \mathrm{yr}$ ) inferred by Kuhi (1964) for T-Tauri protostars of $M \gtrsim M_{\odot}$ scemed to be characteristic of this highly luminous, late phase of contraction along the Hayashi track along which our Sun presumably evolved (Cameron, 1963) and to suggest that both matter and angular momentum transfer to the nebula from the central star is occurring (Low and Smith, 1966; Schwartz and Schubert, 1969). Such a T-Tauri stage, with a time scale $\left(10^{6}\right.$ to $10^{7} \mathrm{yr}$, or shorter) compatible with observations, was in fact incorporated into the cvolutionary history of the Sun in both hydrodynamical (Cameron, 1969) and hydromagnetic (Hoyle and Wickramasinghe, 1968) models of the formation of a solar nebula. Moreover, the enhanced solar winds associated with T-Tauri activity and the magnetic fields presumed to be dragged out with solar plasma and "wound up" have been further incorporated into theorics of early heating of asteroidal bodies, thus accounting for apparent metamorphism in some meteorites (Sonett et al., 1970; Sonett, 1971). The high opacity of T-Tauri dust envelopes and the average grain temperature of $T \sim 600^{\circ} \mathrm{K}$ inferred, agree with the fairly high $\left(\sim 500^{\circ} \mathrm{K}\right)$ "hohlraum" tempcratures needed in Sonett's model of asteroid melting; in Hoyle's model also, the opacity becomes very large when $T \sim 500^{\circ} \mathrm{K}$. In Cameron's model, submicron iron grains, within the size range observed in the so-called "primitive" meteorites (Anders, 1971a; Wood, 1967), give the main contribution to the high nebular opacity leading to convection, mixing, and, finally, to accretion of solids. Moreover, the accretion temperatures for chondritic material were estimated to be within a $100^{\circ} \mathrm{K}$ interval centered about $500^{\circ} \mathrm{K}$ (Anders, 1971a). If gas temperatures across a disk nebula range from $\sim 1500^{\circ} \mathrm{K}$ in the inner region to $\sim 350^{\circ} \mathrm{K}$ at the edges, as inferred for VY CMa from molecular emission (Herbig, 1970), one could perhaps recover both the fast aggregation of metal and silicate grains in the higher temperature region and the finer "smoke" fraction condensed in cooler regions proposed in various models (Wood, 1967; Hoyle and Wickramasinghe, 1968). A similar range for grain temperatures is provided for, if iron grains are to grow in a plasma-gas medium of densities $n \sim 10^{7}$ to $10^{17} \mathrm{~cm}^{-3}$, at $1 \mathrm{AU}$ (Lehnert, 1970; Arrhenius and Alfvén, 1971); the ionization might be maintained by the violent T-Tauri activity. Thus observations of T-Tauri stars do not appear to specifically rule out any of the proposed models, which all scem to be flexible enough to accommodate such an evolutionary stage.

Other recent observations of both hotter, early (A to $\mathrm{F}$ spectral type) pre-main sequence stars (Strom et al., 1971; Woolf et al., 1970) and of late supergiants and variable stars (Gillett et al., 1970) have revealed extensive circumstellar obscuration by gas and dust, either in shell or in disk configurations, to be a general phenomenon. But dust is also widely associated with the generally lower density plasma-gas environments of interstellar clouds $\left(n \lesssim 10^{4} \mathrm{~cm}^{-3}\right)$, where grains at temperatures inferred to range from 10 to $<10^{3 \circ} \mathrm{K}$ are imbedded in generally hotter gas $\left(T \sim 10^{2} \mathrm{~K}\right.$ to $10^{4^{\circ}} \mathrm{K}$ ) (Harper and Low, 1971; Greenberg, 1968) so that $T_{\mathrm{gr}} / T_{\mathrm{gas}} \leqslant 0.1$. Such thermal disequilibrium is an essential feature in the Arrhenius and Alfven (1971) model, with temperature and plasma-gas density regimes for growth of grains defined in Lehnert (1970). It thus appears that most primordial condensation models are at least partially consistent with astronomical observations.

\section{Grain Characteristics}

Grain sizes, such as those observed in the matrix of carbonaceous meteorites $(0.01$ to $1 \mu$ and $>5 \mu)$, 
are not too helpful in determining place of origin; submicron grains are known to be present both in interstellar clouds (Greenberg, 1968) and in envelopes of T-Tauri stars, where larger grains are also present (Low et al., 1970). Only grains larger than a few microns scem to have survived close to the hotter (A-F) stars (Strom et al., 1971), as smaller grains may have been sputter-evaporated in hot stellar winds (Meyer, 1971), or blown out by radiation pressure. In our own solar system, solid grains of $\sim 1 \mu$ sizes have been identified as a plausible source of the infrared continuum of comets (KrishnaSwamy and Donn, 1968), and analyses of zodiacal light indicated grain sizes in the 0.1 to $10 \mu$ range (Greenberg, 1967). A similar size spectrum is observed for laboratory quenched condensation of metallic $\left(\mathrm{Fe}_{\mathrm{c}}, \mathrm{Co}, \mathrm{Ni}\right.$, ete. ) and other $\left(\mathrm{C}, \mathrm{SiO}_{2}, \mathrm{SiC}\right)$ grains of refractory materials (Kimoto et al.; 1963, Kimoto and Nishida, 1967; Lefèvre, 1970) expected to be amongst the earliest condensates (Gilman, 1969; Hoyle and Wickramasinghe, 1968; Arrhenius and Alfvén, 1971 and others). These range from polyhedral to deformed subhedral crystals, showing twinning and stacking faults, to hexagonal plates, to spherulitic silica, to be compared to other expected or observed crystal growth habits (Donn and Scars, 1963; Meyer, 1971).

The observed forms of aggregation for these submicron grains in laboratory condensation may be highly significant: Ferromagnetic metals (Fc, $\mathrm{Ni}, \mathrm{Co}$ ) were generally observed to collect into chains which, if deposited in the presence of a magnetic field, aligned themselves parallel to it. This tendency to shape anisotropy (Kimoto and Nishida, 1967; Lefèvre, 1970; Donn and Sears, 1963) insures stable magnetic moments for ferromagnetic grains (single-domain behavior) over a wide range of sizes (sce Sec. 2). The magnetic energy of cohesion for submicron iron grains was measured and found to be an order of magnitude larger than for microscopic Fe crystals (Tanaka and Tamagawa, 1967). This supports the feasibility of proposed fast aggregation and size fractionation mechanisms for magnetic grains in the solar system (Wood, 1962; Harris and Tozer, 1967 ), discussed below. The clusters of $\sim 10^{3}$ to $10^{4}$ submicron magnetite grains observed in carbonaceous chondrites (Kerridge, 1970) might be attributed to magnetic interactions.

But nonferromagnetic silica grains of similar diameters $(0.02-0.04 \mu ; 0.05-0.08 \mu)$ also formed chains and floccules. For silicate grains of similar size $(\sim 0.02 \mu)$ in the matrix fraction of some primitive carbonaceous chondrites (such as Renazzo) Wood (1962) had proposed flocculation due to the likely electric charging of such grains. An interesting result from studies of growth kinetics (Sutherland, 1970) is that flocculation and chain formation is likely even in the absence of directional mechanisms. In any case, the likelihood of shape anisotropy for submicron grains or assemblies of grains has observational consequences not only in the case of interstellar polarization of starlight due to grain alignment in weak magnetic fields (Greenberg, 1968), but also in the case of the magnetic properties of meteorites (see Scc. 3).

The observationally inferred compositions of cosmic grains also agree well with some metcoritic materials and with the predictions of most condensation models. Silicates have been identified in the infrared in both interstellar and circumstellar dust (Hackwell et al., 1970; Gillett et al., 1970), while in the solar system their presence may be surmised in the zodiacal dust (MacQuecn, 1968), in comets (Maas et al., 1970), and on asteroids (McCord et al., 1970). Iron grains are also likely to be present in interstellar space (Wickramasinghe and Nandy, 1970); in some circumstellar envelopes (Gillett et al, 1970) (where possible infrared excess at $3 \mu$ and $5 \mu$ might be attributed to hot iron grains, at $900^{\circ} \mathrm{K}$ and $\lesssim 500^{\circ} \mathrm{K}$ ) and in comets as submicron grains (Liller, 1960). In Professor Arrhenius' laboratory, meteoritic erystalline silicates were grown directly from the vapor in plasma-sputtering experiments (Meyer, 1971), and Ni-Fe phases similarly produced are being studied by the present author.

\section{GRAINS AND MAGNETIC FIELDS}

\section{Individual Grains in Space}

The existence and duration of the preaggregation grain stage, in the lifetime of meteoritic material can sometimes be inferred for primitive grains in chondrites; for example, it was found that the $(\mathrm{H}, \mathrm{He})$ gas content in small $(<50 \mu)$ pyroxcne grains is concentrated in the outer $(0.5 \mu)$ skin and correlates inversely with grain size (Eberhardt et al., 1965). The solar wind implantation 
of these gases into surfaces of small $(\sim 10 \mu)$ individual silicate grains was studied (Lord, 1969) and was shown to be an efficient mechanism; the high proton contents $\left(4 \times 10^{19}\right.$ to $\left.2 \times 10^{20} / \mathrm{g}\right)$ of several chondrites (Chatelain et al., 1970) implies exposure of grains to the present 1 AU solar wind flux $\left(\sim 2 \times 10^{8} \mathrm{~cm}^{-2} \mathrm{~s}^{-1}\right)$ for $\sim 10^{4}$ equivalent ycars. A similar equivalent exposure age $\left(10^{3}\right.$ to $10^{4} \mathrm{yr}$ ) was inferred for isotropically irradiated individual crystallites in primitive meteorites (Lal and Rajan, 1969; Pellas et al., 1969). Heating to $\sim 500^{\circ} \mathrm{K}$ cannot have occurred during or after the agglomeration of grains and chondrules, or else irradiation damage would have been annealed (sce also Green et al., 1971). These and the implanted noble gas component found in the magnetic grains of the unaltered carbonaccous chondrite Orgueil (Jeffery and Anders, 1970), imply that grains must have been individually suspended and exposed to cosmic irradiation in space, post-condensation and prior to agglomeration, during $\lesssim 10^{4}$ yr. This might well have occurred during a "jet stream" stage (Alfvén and Arrhenius, 1970) or during the $\sim 5 \times 10^{3} \mathrm{yr}$ estimated for the completion of angular momentum and matter transfer to the outer nebula (Hoyle and Wickramasinghe, 1968), and is not incompatible with most condensation models.

\section{Magnetic Fields and Grain Alignment}

In several studies (Spitzer and Tukey, 1949; Jones and Spitzer, 1967) attempting to explain the polarization of starlight by a partial alignment of elongated ferromagnetic or ferrite interstellar grains in weak magnetic fields, it has been shown that fields of $5 \times 10^{-5}$ to $5 \times 10^{-8}$ gauss would effectively align both single domain $(\sim 0.01$ to $1 \mu$ ) and larger, multi-domain grains, as well as "superparamagnetic" clusters of fine ferromagnetic particles imbedded in the nonmagnetic matrix of a host grain. Alignment of dia- or para-magnetic grains would require higher fields of lower grain temperatures (Greenberg, 1968). It was confirmed by a study (Purcell, 1969) on the efficiency of various alignment mechanisms that the degree of shape anisotropy and the temperature ratio $T_{\mathrm{grain}} / T_{\mathrm{gas}}$ are crucial parameters. A low $T_{\mathrm{gr}} / T_{\mathrm{gas}}$ ratio is required, such as the obscrvationally inferred values $(\leqslant 0.1)$ for "dense" HI, and HII interstellar clouds (Harper and Low,
1971) and such as featured in the "cool grains-hot gas" non-equilibrium plasma-condensation model of Arrhenius and Alfvén (1971) and in the laboratory condensation work on which it is based. Moreover, in a partially ionized protoplanetary nebula in which the ionization controlled sequential condensation of species takes place with simultaneous fractionation, the parameters derived by Jokipii (1964) to account for the observed noble gases abundance pattern determine the magnetic field value at $1 \mathrm{AU}$ to be $B \gtrsim 5 \times 10^{-5}$ gauss, similar to the present observed interplanetary field value in our neighborhood.

Could this field value partially align anisotropic ferromagnetic grains? Consider the additional requirements $\delta=\tau_{\text {coll }} / \tau_{\text {mag }} \lesssim 1$ for partial alignment of grains (Purcell, 1969), where $\delta \propto$ $B^{2} / a \rho_{\mathrm{gas}} v_{\mathrm{gas}}$, is the ratio of collisional to magnetic relaxation times. If, for a given value of the parameter $\delta$, only the number density of atoms, $n$ is allowed to increase from interstellar values, then a field of $\sim 10^{-5}$ gauss at $n \sim 10^{7} \mathrm{~cm}^{-3}$ may align ferromagnetic and ferritic grains as effectively as $\sim 10^{-8}$ gauss at $n \sim 10 \mathrm{~cm}^{-3}$. But, if $n \sim 10^{17}$ $\mathrm{cm}^{-3}$, as required for growth of iron grains in hydrogen (Lehnert, 1970), a field of $\sim 1$ gauss will be needed to achicve a comparable degree of alignment. If the distributed density in the asteroid belt was indeed five orders of magnitude lower than in the terrestrial and jovian region during accretion, as it is today (Alfvén and Arrhenius, 1970), then partial grain alignment could have been achieved even by $\sim 10^{-5}$ gauss interplanetary fields. Varying degrees of anisotropy of the magnetic susceptibility were found in chondrites (Stacey et al., 1961; Weaving, 1962) testifying to partial alignment of elongated $\mathrm{Fe} / \mathrm{Ni}$ grains in the stony matrix by some orienting agency, very likely by both magnetic fields and by enhanced solar winds (Greenberg, 1967, 1970). This evidence will be discussed below in the context of similar occurrences in terrestrial rockmagnetism (Sec. 3).

The role possibly played by the magnetic fields in the early solar system consists not only in transferring material and angular momentum to the periphery of the condensing disk and helping establish the large scale physico-chemical distribution observed, but also in leading to finestructure chemical fractionation, as a result of ambipolar diffusion (Arrhenius and Alfvén, 1971). 
Moreover, as pointed out by Spitzer (1963), not only is ambipolar diffusion helped by grains, but submicron grains help maintain the magnetic field and slow down its decay, by supporting a current system as they bccome partially charged in the plasma. Such small grains, with large surface-to-volume ratio, could perhaps flocculate by interacting electrostatically (Wood, 1962) and form chondritic matrix-like aggregates.

On the other hand, magnetic fields are not explicitly integrated into the "chemical" models (Anders, 1971a) although it is generally conceded that the ferromagnetism of meteoritic $\mathrm{Ni} / \mathrm{Fe}$ grains, as they cooled below their Curic tempcrature $\left(T_{c} \lesssim 900^{\circ} \mathrm{K}\right)$, triggered the metal-silicate fractionation which lead to loss of metal from the iron-rich material of $\mathrm{Cl}$ and $\mathrm{H}$-chondrites. Harris and Tozer (1967) suggested that magnetic interactions might enhance the capture cross-section of 1 to $10 \mu$ ferromagnetic grains by a factor of $\sim 10^{4}$, leading to rapid aggregation into clusters of $10^{3}$ to $10^{4}$ grains. This type of clusters of grains was indeed observed for magnetite spherules of $(0.1$ to $1 \mu)$ in the "primitive" carbonaceous chondrite Orgueil (Kerridge, 1970). This process might have, in turn, led to a size fractionation process in a protoplanetary nebula whereby large aggregates of ferromagnetic grains could have been preferentially retained in the inner regions, while single domain-size grains $(0.03$ to $0.05 \mu)$ could have been carried outward by a violent solar wind during a T-Tauri stage (Sonett et al,, 1970). Let us examine the modes of acquisition of remanence for a growing grain, immersed in an ambient field.

\section{Magnetization of Grains}

The quantity determining the stability of a grain's magnetization $M$ is a relaxation time (Irving, 1964), $\tau \propto \exp v \Delta E / k T$ (where $v$ is the volume of magnetic material, $\Delta E$ is an energy barrier to magnetization reversal proportional to the coercivity $H_{c}$, and $T$ is the grain temperature). This connects clearly the stability of a grain's magnetization to a critical volume at a given $T$, or to blocking temperature for a given grain size. Below a critical size $d_{B}$, the grain is superparamagnetic, its magnetic moment being rendered unstable by thermal fluctuations, and no remanence is acquired. Doubling the grain volume at constant $T$ may incrcase $\tau$ by ten orders of magnitude (sce fig. 1). Above $d_{B}$, stable single domain behavior is exhibited, up to a critical size for multi-domain configuration of lower remanence and stability. The transition from the superparamagnetic to single- to multi-domain regime of magnetization is illustrated in figure 2 for magnetite, at several temperature values (Strangway et al., 1968). Note that critical diameters for single domain behavior are $d \gtrsim 0.03 \mu$ and $0.05 \mu$ for $\mathrm{Fe}$ and Ni respectively, but at elongation $\ell / d \sim 10$, the critical sizes increase to above $0.12 \mu$ and $0.21 \mu$, and to generally larger sizes for ferrites (Jones and Spitzer, 1967) as illustrated in figures 1 and 2. Thus, the stability of the remanent magnetization acquired depends on the ratio $v / T$. If, at constant $T$, the magnetization becomes "blocked" as the growing grain reaches the critical size $d_{B}$, the stable moment is a CRM. If, at constant $v$, the temperature of the cooling grains reaches the blocking value (within $\sim 100^{\circ} \mathrm{C}$ below the Curie point $T_{c}$ ), a TRM is acquired. If the cooling and growth processes are simultancous, a more complex TCRM is established. Both TRM and CRM have similar stability characteristics, figure $3(\mathrm{a})$, (Kobayashi, 1959), but CRM is an order of magnitude lower than a TRM acquired in very weak fields $\lesssim 1$ Oe. Morcover TRM $\propto H$ holds for $H \lesssim 2$ Oe and saturation can

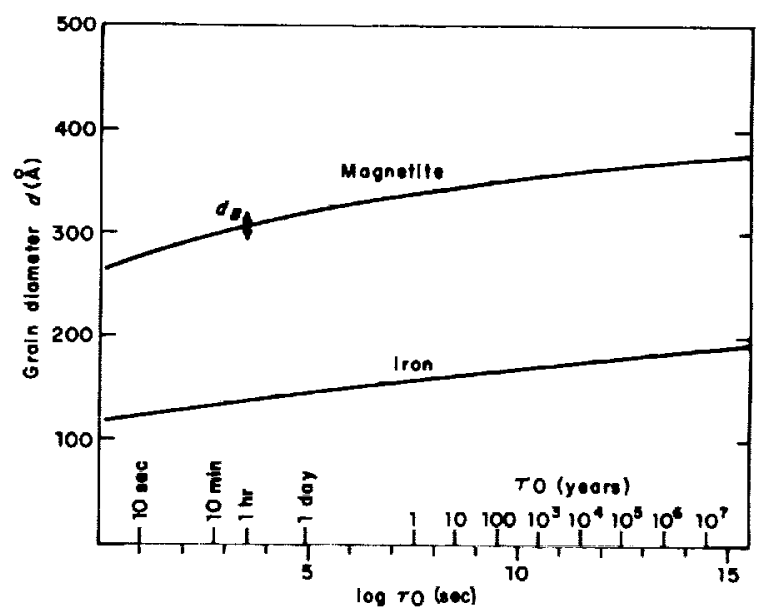

FIgure 1.-The dependence of the relaxation time $\tau_{0}$ on grain diameter, at room temperature, for iron and magnetite. (Reproduced from Irving, 1964.) 
set in, but $\mathrm{CRM} \propto H$ up to 50 Oe. Both have identical values in $\sim 30$ Oe fields, and become even harder to distinguish (Banerjee, 1970). Not only shape anisotropy (Strangway et al., 1968), but also ferromagnetic impurities in a less magnetic grain (Jones and Spitzer, 1967) as well as dislocations and defects in crystals (Verhoogen, 1959) may increase the critical size for single domain behavior and stabilize the remanence in large, multi-domain grains (pseudo-single domain grains of magnetite may reach $\sim 40 \mu$ size). As the small magnetic grains accrete into a rock complex, they may acquire depositional remanence (DRM) and remain partially aligned in the matrix. If the complex "sets" from high temperatures in the presence of a field, a high coercivity remanence will result from the alignment of anisotropic grains (Stacey, 1960a, b). The effect of interactions between magnetic grains in a matrix is to

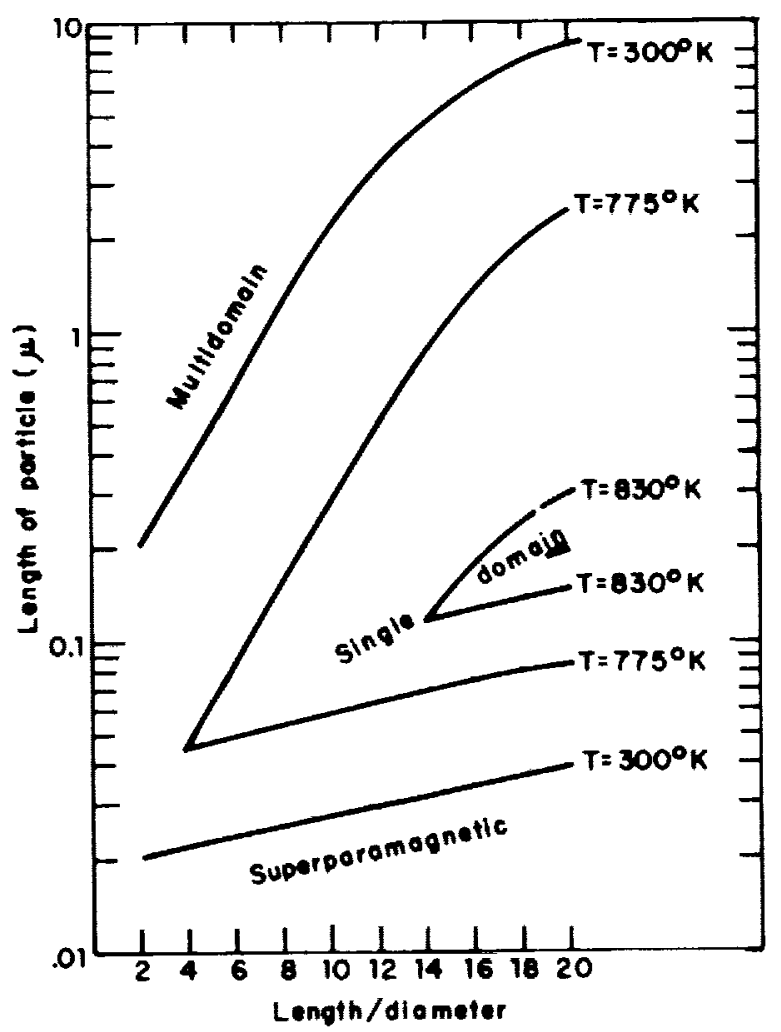

Figrre 2.-The range of grain sizes for single domain behavior in magnetite, as a function of shape anisotropy and temperature. (Reproduced from Strangway et al., 1968.) also increase the critical size but to reduce the coercivity (fig. 4 and Haigh, 1958) and the small field TRM (Dunlop and West, 1969). The CRM is not decreased by interactions, so that the only difference between TRM and CRM, namely their relatively low field intensity, may be erased for interacting grains in a meteorite or rock. In a rock, even a small fraction of single domain grains will dominate the magnetic properties, as it will have preserved the stablest remanence. The presence of such grain fraction had been known to exist in tektites (Senftle et al., 1964; Thorpe and Senftle, 1964), has been established for car-

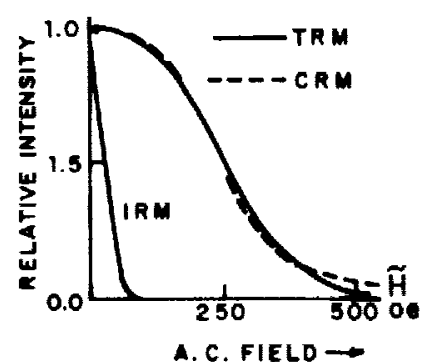

(a)

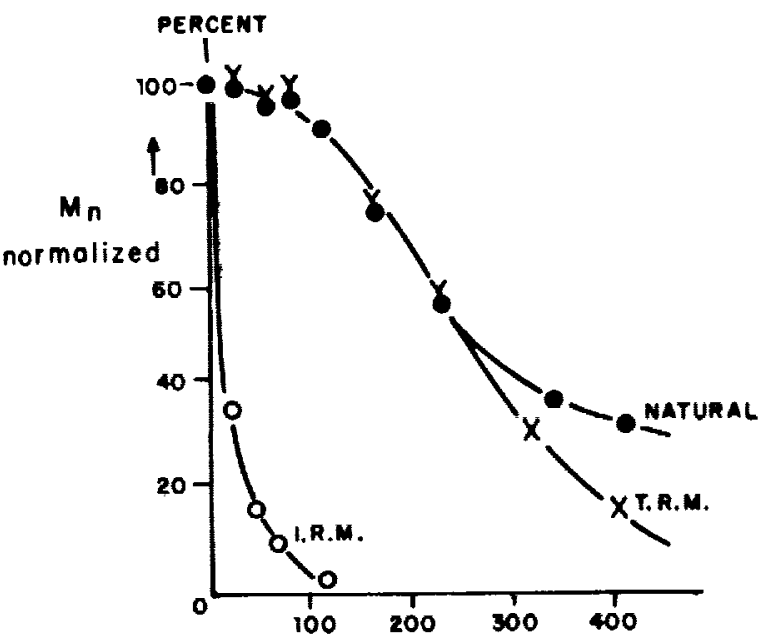

(b)

FIGURE 3--(a) Characteristic behavior of IRM and weak field TRM and CRM in AF demagnetization (after Banerjee, 1970). (b) Stability of NRM vs artificial TRM and IRM in the Brewster chondrite (from Weaving, 1962). By comparing with (a), the NRM appears to be a CRM. 


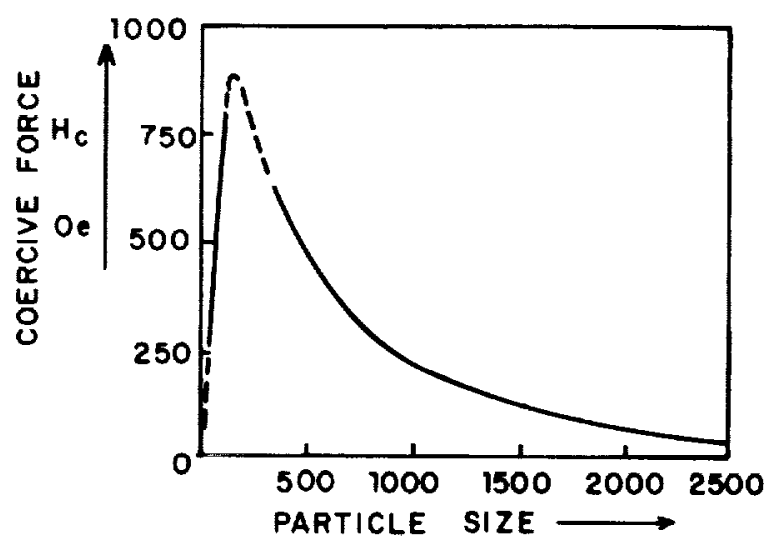

FIGURE 4.-Coercivity dependence on grain diameter, for iron (from Haigh, 1958).

bonaccous chondrites (Kerridge, 1970) and only very recently, for terrestrial igneous rocks (Evans and Wayman, 1971). If chemical and crystalline phase changes continue to occur after the accretion of grains into a rock-like complex, CRM's will ensue (Kobayashi, 1959; Haigh, 1958). If cooling below the Curie points of various materials (sce table 1) takes place after accretion, a TRM will be acquired. If the grain, such as $\mathrm{Ni} / \mathrm{Fe}$ meteoritic grains, crystallized or grew directly from the vapor phase below $T_{c}$ (Arrhenius and Alfvén, 1971), and continued to cool, a partial thermoremanence (P)TRM could compound the initial CRM. A complex NRII of this type may also be expected for iron meteorites, where the crystalline ordering obscrved is attributed to diffusional changes during slow prolonged cooling (Goldstein, 1969). At constant temperature, in a steady field an isothermal remanence (IR.I) may be acquired, which in general, is the less intense and the least stable among remanence types (Irving, 1964).

\section{THE MAGNETIC PROPERTIES OF METE- ORITES AND THEIR INTERPRETA- TION, WITH REFERENCES TO ROCK MAGNETISM}

\section{Paleomagnetic Methods}

The most widely used methods of palcomagnetic analysis are:

(a) Thermal demagnetization, which removes remanence components unstable above a certain temperature and reveals the carrier phases as the changes in NRM occur close to the Curie points $\left(T_{c}\right)$ (see table 1). This method is marred by chemical and erystal phase changes upon heating and cooling.

(b) Alternating-field (AF) demagnetization, which removes the NRM components with a coercivity lower than a selected peak amplitude $H_{A F}$. It may introduce artificial anisotropies, and anhysteretic secondary remanence (ARM). (For a full discussion of subtleties involved, see Irving, 1964; Schwartz, 1969; Doell and Smith, 1969.)

(c) Demagnetization by steady fields (dc), which determines the cocreivity $H_{c}$ of the NRM, or the field value needed to erase the NRM. The value of the destructive field depends on the fraction of grains with a given coercivity. In general, a rock may be described as an assemblage of ferromagnetic or ferritic (see table 1) grains imbedded in an inert or less magnetic matrix. A spectrum of grain sizes, will lead to a spectrum of micrococrcivities, and blocking temperatures in demagnetization studies. The bulk coercivity $H_{c}$ is a qualitative guide to stability, or "hardness" of remanence only. A high value for $H_{c}$ does indicate high stability (bulk "hardness"), but a low $H_{c}$ value implics only that a large fraction of grains has low coercivity ("soft") though a small, highly stable grain fraction may exist.

The remanent properties of a rock are expressed in its NRM intensity $\left(M_{n}\right.$, the magnetization, is given in gauss; or as specific intensity per unit density $M_{n} / \rho$; or as volume intensity $M_{n} / v$ ) and in its susceptibility $\chi$, usually expressed as the induced moment in unit field per $\mathrm{cm}^{3}$ or per gram in cgsm. For terrestrial rocks, $M_{n}$ is in the range $\sim 10^{-4}$ to $10^{-2} \mathrm{emu} / \mathrm{cm}^{3}$ for igneous rocks, but $10^{-6}$ to $10^{-8} \mathrm{emu} / \mathrm{cm}^{3}$ for the sedimentary type.

\section{Remanence in Meteorites, Tektites and Moon Samples, Its Character and Possible Origins}

The most recent and complete survey of the magnetic properties of meteorites is that of Guskova and Pochtarev (1969), some of whose earlier results are reproduced in figure 5 and table 2. To summarize: For stony meteorites, a direct dependence of the specific susceptibility $\chi$ on the $\mathrm{Ni} / \mathrm{Fe}$ content was found increasing from 10 to 
Table 1,-Some Characteristics of Magnetic Phases in Meteorites

\begin{tabular}{|c|c|c|c|}
\hline Phase & Type & $T_{C}$ or $T_{N}$ & $M_{s}(e m u / g)$ \\
\hline $\begin{array}{l}\mathrm{Ni}-\mathrm{Fe}: \alpha(\text { kamacite }) \\
\quad \alpha+\gamma \text { (plessite) } \\
\quad \gamma(\text { taenite) } \\
\mathrm{Fe} \\
\mathrm{Ni} \\
\mathrm{Fe}_{3} \mathrm{O}_{4} \text { (magnetite) } \\
\mathrm{NiFe}_{2} \mathrm{O}_{4} \text { (trevorite) } \\
\mathrm{MnFe}_{2} \mathrm{O}_{4} \\
\mathrm{MgFe}_{2} \mathrm{O}_{4} \\
\mathrm{FeS}_{1+}(0<x<0.15) \text { (pyrrhotite) } \\
\left(\mathrm{Fe}_{1} \mathrm{Ni}_{3} \mathrm{P}\right. \\
\left(\mathrm{Fe}, \mathrm{Ni}_{3} \mathrm{C}\right. \\
\mathrm{FeS} \text { (troilite) } \\
\mathrm{Fe}_{2} \mathrm{SiO}_{4} \text { (fayalite) } \\
\mathrm{FeSiO}_{3} \text { (pyroxene) }\end{array}$ & $\begin{array}{l}\text { Ferromagnetic } \\
\text { Ferromagnetic } \\
\text { (Paramagnetic) } \\
\text { Ferromagnetic } \\
\text { Ferromagnetic } \\
\text { Ferrimagnetic } \\
\text { Ferrimagnetic } \\
\text { Ferrimagnetic } \\
\text { Ferrimagnetic } \\
\text { Ferrimagnetic } \\
\\
\text { Antiferromagnetic } \\
\text { Antiferromagnetic } \\
\text { Antiferromagnetic }\end{array}$ & $\begin{array}{c}7750^{\circ} \mathrm{C} \\
400-600^{\circ} \mathrm{C} \\
0-600^{\circ} \mathrm{C} \\
770^{\circ} \mathrm{C} \\
358^{\circ} \mathrm{C} \\
580^{\circ} \mathrm{C} \\
585^{\circ} \mathrm{C} \\
300^{\circ} \mathrm{C} \\
440^{\circ} \mathrm{C} \\
320^{\circ} \mathrm{C} \\
\leq 420^{\circ} \mathrm{C} \\
\leq 215^{\circ} \mathrm{C} \\
320^{\circ} \mathrm{C} \\
126^{\circ} \mathrm{K} \\
40^{\circ} \mathrm{K}\end{array}$ & $\begin{array}{c}\text { iron meteorites }\left\{\begin{array}{r}90-140 \\
180-220\end{array}\right. \\
\sim 218 \\
\sim 54.4 \\
92 \\
51 \\
84 \\
24.5 \\
<19.5\end{array}$ \\
\hline
\end{tabular}

$20 \times 10^{-3} \mathrm{cgsm}$ for the L- (low iron $\sim 7$ to 12 percent $\mathrm{Ni} / \mathrm{Fe}$ ) to $\sim 50$ to $60 \times 10^{-3} \mathrm{cgsm}$ for the H- (high iron) subgroup (Guskova, 1963), with the lowest values of 0.2 to $3.5 \times 10^{-3} \mathrm{cgsm}$ for the $\mathrm{Ni} / \mathrm{Fe}$ poor (2 to 3 percent wt.) achondrites (Pochtarev and Guskova, 1962). The range for $M_{n}$ is 0.5 to $40 \times 10^{-3} \mathrm{cgsm}$. For stony-irons, with a volumetric fraction of $\mathrm{Ni} / \mathrm{Fe}$ of $\sim 50$ percent, $M_{n} \sim 5$ to $70 \times 10^{-3} \mathrm{cgsm}$ and $\chi$ is up to 0.2 to $1 \mathrm{cgsm}$. For iron meteorites an inverse correlation between the volume susceptibility and the Ga-Ge content was found (table 2), $\chi$ and $M_{n}$ increasing from group I to IV. The range for $\chi$ is 0.8 to $4 \mathrm{cgsm}$, and for $M_{n} \sim 10$ to $300 \times 10^{-3}$ cgsm, with the finest structured octahedrites exhibiting the highest remanence. The range of coercivity is from a low $H_{c} \sim 0.5$ to $1.5 \mathrm{De}$ for iron metcorites to values of $\sim 5$ to 20 Oe for chondrites. It was thought (Pochtarev, 1967; Stacey et al., 1961) that these low $H_{c}$ valucs (to be compared to $H_{c} \sim 60$ to 220 Oe for terrestrial igncous rocks) confirm that the coarsely crystalline strueture of the metal $\mathrm{Ni} / \mathrm{Fe}$ phases in meteorites (Wood, 1967; Goldstein, 1969), is magnetically "soft," and cannot have preserved useful paleomagnetic information. This belief was shown to be erroneous by the finding (Guskova, 1963) of a "hard" NRM component in chondrites, stable to $H_{A F} \sim 300 \mathrm{Oe}$ and $T \sim 800^{\circ} \mathrm{C}$, i.e., of TRM stability type. Even though stony and stony-iron meteorites showed both a "soft" and a "hard" remanence to be present (Guskova and Pochtarev, 1967; Stacey and Lovering, 1959; Stacey et al., 1961), only a "hard" component was found in iron meteorites. It was realized that this "hard" NRM could be either a CRM or a TRM (Stacey and Lovering, 1959), or more likely, a TCRM acquired as the high temperature $\gamma-\mathrm{Ni} / \mathrm{Fe}$ phase transformed to the strongly ferromagnetic $\alpha-\mathrm{Ni} / \mathrm{Fe}$ phase, which further cooled in an external field in the neighborhood of $T_{c}$, the equilibration between the alloy phases procecding down to $T \sim 400^{\circ} \mathrm{C}$. Nevertheless, the stable NRM components were simplistically treated as pure TRM's acquired during cooling in a dipole field like the Earth's (with values of $H \sim 0.15$ Oc experienced for the stony fraction and $H \sim 0.6$ Oe for the iron corc, on a parent planet differentiated by zonal melting (Guskova and Pochtarev, 1967; Pochtarev, 1967).

The more subtle fact is that, in this planetary model for the parent body, the iron meteorites which derived from its core should not have shown any NRM because the field would have decayed already above $T_{c} \leqslant 770^{\circ} \mathrm{C}$ at the time of their solidification (Stacey et al., 1961). It can be argued on several grounds that an interpretation of the "hard" NR.M as a CRM is more plausible. In fact it was found (Pochtarev, 1967) that a best fit of chondritic remanence to theoretical TRM 


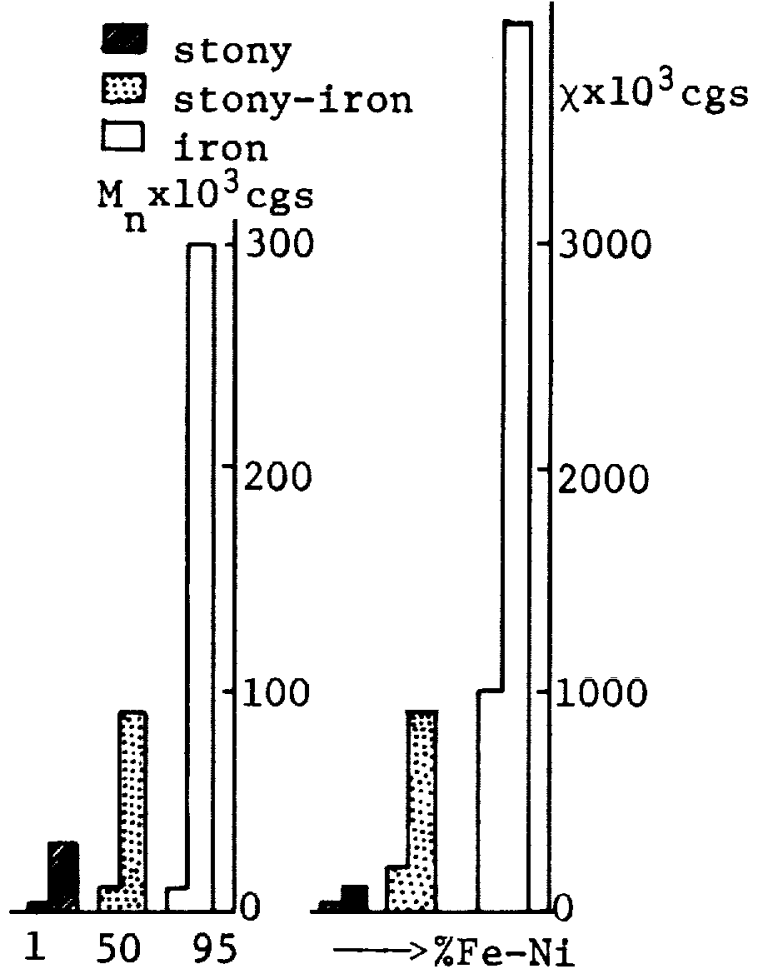

Figure 5.-The intensity of NRM $\left(M_{n}\right)$ and the susceptibility $(x)$ of meteorites, correlated with $\mathrm{Ni} / \mathrm{Fe}$ content (from Guskova and Pochtarev, 1967). models requires a value for the parameter $\sigma_{\mathrm{RT}} / \sigma_{\mathrm{BT}}$ (ratio of spontaneous magnetization at room vs blocking temperature) of 1.5 to 2 , compared to values of $\sim 3$ for normal TRM, and to values $\gtrsim 1$ expected for CRM (Stacey et al., 1961), thus suggesting that a CRM component is present. Moreover, CRM's had repeatedly been mistaken for TRM's in terrestrial rock magnetism, because of their identical stability to AF demagnetization (Banerjee, 1970). A comparison of figure 3(a) with figure $3(\mathrm{~b})$ suggests that the NRM of the chondrite Brewster (Weaving, 1962) does appear to behave more like CRM than TRM.

There have been many, varied arguments advanced against a theory of an origin of meteorites in a single planetary parent body in general, and against an origin of iron meteorites in the core of one or a few large differentiated bodies, in particular (Levin, 1969; Anders, 1971b; Goldstein, 1969; Buseck and Goldstein, 1968; Fricker et al., 1970). The arguments will not be repeated here, but they further weaken the case for a simple TRM acquired in the field of a terrestrial type planet (Pochtarev, 1967; Guskova and Pochtarev, 1967), and make the various estimates of paleointensity of $\mathrm{H} \lesssim 1 \mathrm{Oe}$, rather doubtful. Furthermore, in iron meteorites, a considerable thermal

TABLE 2.-The Anticorrelation of Ga-Ge Content and the Magnetic Susceptibility for Iron Meteorites

\begin{tabular}{c|c|c}
\hline \multicolumn{3}{c}{ From Guskova and Pochtarev (1969) } \\
\hline Ga-Ge group & Mn $\left(\times 10^{3} \mathrm{cgsm}\right)$ & $\times\left(\times 10^{3} \mathrm{cgsm}\right)$ \\
\hline I & 30 & 1500 \\
IIIa & 60 & 1600 \\
IIIb & 70 & 1700 \\
IVa & 120 & 1100 \\
\hline
\end{tabular}

From Guskova (1963)

\begin{tabular}{c|c|c|c|c}
\hline Group & Ga, ppm & Ge, ppm & Mn $\left(\times 10^{3} \mathrm{cgsm}\right)$ & $x\left(\times 10^{3} \mathrm{cgsm}\right)$ \\
\hline & $80-100$ & $300-420$ & & \\
I & $40-65$ & $130-230$ & 36 & 580 \\
II & $8-24$ & $15-80$ & 300 & 660 \\
III & $1-3$ & $<1$ & 300 & 670 \\
IV & & & 1000 \\
\hline
\end{tabular}


hysteresis - due to crystal phase transformations $(\alpha \rightleftarrows \gamma)$ particularly in the plessitic, fine grained $(<\mathrm{I} \mu)$ fraction of $\mathrm{Ni} / \mathrm{Fe}$, and to oxidation or decomposition of secondary magnetic phases such as sulfides, phosphides, carbides-would preclude a reliable estimate of the paleointensity being made from thermomagnetic analyses. Some experiments for testing the suitability of meteoritic samples for palcointensity determinations are suggested in Section 4. An important observation suggesting the continued presence of a magnetic field from the condensation and growth of grains through the aggregation stage (see Sec. 2) is that of the anisotropic susceptibility in chondrites, and, perhaps of the unusual type of crystalline anisotropy found in iron meteorites (Staccy et al., 1961; Weaving, 1961). The various degrees of anisotropy $\left(\chi_{\max } / \chi_{\min } \sim 1.4\right.$ to 2.1$)$ in chondrites were concluded to be due to partial alignment of elongated metal grains along the direction of maximum $x$, reminiscent of "stringing" observed in artificial powder samples of $\mathrm{Fe}, \mathrm{Ni}$, $\mathrm{Fe}_{3} \mathrm{O}_{4}$, set in a magnetic field (Stacey, 1960a, b). Moreover, the orienting action of streaming solar winds (Greenberg, 1967, 1970), especially if a T-Tauri type activity did take place, should also contribute to the alignment of elongated grains inferred from magnetic anisotropy. Such a grain fraction, even though of large physical sizes (Wood, 1967) (10 to $100 \mu$ ), could carry stable remanence (Strangway et al., 1968; Dunlop and West, 1969). Pseudo-single domain behavior of large irregularly shaped, or anisotropic (lamellar, acicular) grains could be attributed to slip dislocations (Bozorth, 1951), to inclusions (such as phosphides, sulfides and carbides in the $\mathrm{Ni} / \mathrm{Fe}$ ), or to any other structural and compositional inhomogeneities, such as the $\mathrm{Ni}$ concentration in the Ni-Fe alloy. Magnetic "hardening" of grains could result also from cosmic irradiation during growth which may cause surface damage in the growing grain and implant nonmagnetic impurities, such as protons (Sec. 2). Annealing in hydrogen is known to improve the magnetic susceptibility of $\mathrm{Ni} / \mathrm{Fe}$ alloys (Bozorth, 1951), and electrolytically implanted hydrogen can cause magnetic "hardening" of iron grains. Thus, if growing in a hydrogen-rich gas and/or being exposed to solar winds (Sec. 1), even large grains may have preserved a stable remanence. All such assemblies of irregularly shaped grains could be reduced to equivalent ellipsoids (Brown, 1960) and treated by "fine-particles" or "inclusion" theories (Kneller, 1969) devised for ferrite permanent-magnet materials. For tektites (Senftle et al., 1964; Thorpe and Senftle, 1964), stable remanence was found to reside in submicroscopic spherules of $\mathrm{Ni} / \mathrm{Fe}$ with $\sim 23$ percent $\mathrm{Ni}$; an alloy in this composition range has the highest possible coercivity (Bozorth, 1951). In lunar microbreccia and rocks, a very stable, high coercivity $\left(H_{\mathrm{c}} \sim 100\right.$ to $200 \mathrm{Oe}$ ) remanence was found to reside in either native or meteoritic iron grains (Strangway et al., 1970; Doell et al., 1970; Nagata et al., 1970). Weak field susceptibilities of $\sim 10^{-3} \mathrm{emu} / \mathrm{g}$, similar to chondritic values, were found for tektites and lunar samples, the intensity of remanence correlating with the iron content. It appears likely that for all these types of materials, fine particle models could be used to account for observed magnetic properties.

In the case of iron meteorites, the "hard" remanence found is perhaps more difficult to understand, given the macroscopic bandwidths of the ferromagnetic kamacite $(\alpha-\mathrm{Ni} / \mathrm{Fe}$ with $T_{c} \lesssim 770^{\circ} \mathrm{C}$, depending on $\mathrm{Ni}$ content) ranging from $<0.2 \mathrm{~mm}$ in the finest octahedrites to $>\mathbf{2 . 5}$ $\mathrm{mm}$ in the coarsest; the kamacite bands are separated by Ni-rich, paramagnetic taenite $(\gamma-\mathrm{Ni} / \mathrm{Fe}$ ) bands of $\$ 100 \mu$ widths (Goldstein, 1969). But in hexahedrites, Neumann slip bands separating thin (1 to $10 \mu$ ) kamacite lamellae; in octahedrites, inclusions and precipitations, often as oriented lamellae (phosphates and sulfides), as well as compositional inhomogeneities attributed to diffusional equilibration of $\mathrm{Ni}$ in the cooling alloy phascs; and in the Ni-rich ataxites the spindles of 10 to $100 \mu$ of kamacite separated by tacnite lamellae-all could contribute to the "hard" component of NRM. A relevant example (Irving, 1964) from rock magnetism is the high stability of the CRM found for hematite-rich macroscopic lamellae ( 1 to $10 \mathrm{~mm}$ long, 5 to $20 \mu$ thick) evolved from an ilmenite ground mass.

Or, the "hard" component may originate in the crystalline ordering of the $\alpha-\gamma \mathrm{Ni} / \mathrm{Fe}$ phases. A "memory" effect (see Sec. 4) was found (Stacey et al., 1961) for the high temperatures $(T \approx 630$ to $800^{\circ} \mathrm{C}$ ) component of the NRM, which reappeared with the same intensity and direction upon cooling under $T_{c}$, after repeated demagnetizations. These suggest another class of 
permanent magnet materials, namely the diffusion-or dispersion-hardened alloys (Kneller, 1969). They consist of two crystalline phases, one being strongly ferromagnetic (like $\alpha-\mathrm{Ni} / \mathrm{Fe}$ ) and the other weakly-or nonmagnetic (like $\gamma-\mathrm{Ni} / \mathrm{Fe})$; the ferromagnetic phase is dispersed either as "islands" or as plates scparated by nonmagnetic layers, with the highly oriented structure being established by cooling in a magnetic field. In many magnetically annealed anisotropic materials, some crystal axes are preferentially aligned. The crystalline anisotropy which gives rise to the "memory" cffect for the high- $T$ remanence in iron meteorites, may have led to the highly oriented $\alpha-\gamma$ ordering (the Widmannstätten pattern). The NRM could have, of course, been established as a TCRM, as cooling and phase-changes occurred simultaneously in the $\mathrm{Ni} / \mathrm{Fe}$ alloy (Goldstein, 1969), but an interesting possibility, now being experimentally explored by our group, is the simultaneous condensation of $\alpha$ and $\gamma$ phase (Arrhenius and Alfvén, 1971) from the vapor, below $T_{c}$, in the presence of a magnetic field. If the growth takes place in the filmconfiguration, demonstrated "contact" control and "remote" control of the magnetization by the earliest deposit exceeding critical thickness, could establish the direction of the CRM throughout the growing solid. Maurain's (1901) pioneering study of CRM acquired during controlled growth of Fe films in magnetic fields, demonstrated that the critical single domain thickness for films deposited in an ambient magnetic field was $\sim 200 \mu$ for $\mathrm{Ni}$ and $\sim 85 \mu$ for $\mathrm{Fe}$, more than two orders of magnitude larger than for layers deposited in the absence of ficld. It is thus possible that an extremely stable CRM was recorded in the thick ordered layers of $\mathrm{Ni} / \mathrm{Fe}$ growing in the $\alpha+\gamma$ duplex field of temperature. It can therefore be surmised that a stable CRM could have been acquired, already in the carly stages of growth of magnetic solid grains in space, and that field information on this condensation environment could be retricved, if approached expcrimentally in a suitable way.

\section{Fields and Remanence in Various Models}

Kceping in mind the field values ( 0.1 to 1 gauss) required to establish the NRM of meteorites, if it were a TRM, what values of ambient fields might one expect in various models? The strong magnetic field (of $H \sim 100$ gauss) at the Sun's surface for an expanded radius $R_{0} \gtrsim 3 \times 10^{12} \mathrm{~cm}$ (implying $H \sim 10^{-2}$ gauss at $1 \mathrm{AU}$ for a dipole $\sim 1 / R^{3}$ fall-off, or $\sim 4$ gauss if a solar wind $\sim 1 / R^{2}$ fall-off is assumed), required to complete the angular momentum transfer in $\tau \sim 5 \times 10^{3} \mathrm{yr}$ in Hoyle's model, could have decayed to the present interplanetary value of $\gtrsim 5 \gamma=5 \times 10^{-5}$ gauss required by Jokipii (1964) to account for noble gas fractionation by ambipolar diffusion, at $1 \mathrm{AU}$, by the end of the Helmholtz contraction time of $\sim 10^{7}$ yr (Hoyle and Wickramasinghe, 1968; Cameron, 1969). Thus, at least for a short time interval, field values of a few tenths of a gauss could have been attained in the asteroid belt region, (perhaps with simultancous cooling below $T_{c}$ ) and TRM's were acquired. In another scheme, Sonett et al. (1970) and Sonett (1971) proposed a disturbance field of $\sim 0.3$ gauss at $3 \mathrm{AU}$ in order to achicve short lived $\left(<10^{6} \mathrm{yr}\right)$ heating of asteroids, during a T-Tauri phase. For a maximum allowed field at Sun's surface of $\sim 20$ gauss (with a decay time of $\sim 2.2$ billion yr) steady fields at $1 \mathrm{AU}$ may reach values of $50 \gamma$ for $\sim 1 / R^{2}$ fall off. But the early rapid spin of the Sun is supposed to lead to field amplification by $\times 10^{3}$ due to "winding-up" of field lines. The values then may become $\sim 0.5$ gauss at $1 \mathrm{AU}$, and lower by one magnitude at $3 \mathrm{AU}$. It thus appears that, in this case also, partial thermoremanence might have been acquired by meteoritic material, depending on the size of the parent body and location within it, which determine the degree and duration of the heating episode. Many other parameters (Sonett, 1971) must be guessed at, before values of induction fields and (P)TRM's can be evaluated in this model. Chemical changes, and therefore CRM's, are also likely to occur in reheated material; or, if only mildly rehcated, carlicr remanence of either type acquired prior to accretion into parent bodies may have survived. In general, the Thellier method of inferring the paleofield from $H_{\text {ancient }}=$ $H_{\text {known }}$ (NRM/TRM), by comparing NRM with an artificial TRM (acquired by first heating the sample above $T_{c}$, then allowing it to cool in a known field), may not be warranted. Unfortunately, little is known about field intensities needed to establish CRM at growth and crystal- 
lization of solids, as experiments in this area are lacking.

\section{SUGGESTIONS FOR EXPERIMENTAL WORK IN METEORITIC PALEOMAGNETISM}

A most important recent development in meteoritic magnetism is the finding of a sizeable stable, high-coercivity NRM of $\sim 10^{-3}$ to $10^{-5}$ gauss $\mathrm{cm}^{3} / \mathrm{g}$ in several "primitive" carbonaceous chondrites (Types I, II) (Banerjec and Hargraves, 1971). The authors realized that this stable NRM could be used to infer on the paleointensity of magnetic fields in the solar nebula. They were also aware that the NRM could be either a CRM, acquired during the growth of $\mathrm{Ni} / \mathrm{Fe}$ grains in a magnetic field; or a TCRM, acquired when and if $\mathrm{Ni} / \mathrm{Fe}$ grains were oxidized into magnetite $\left(\mathrm{Fe}_{3} \mathrm{O}_{4}\right)$ and trevorite $\left(\mathrm{NiFe}_{2} \mathrm{O}_{4}\right)$, and subsequently cooled; or perhaps a (P)TRM acquired during cooling in the field of their parent body. Unfortunately, the authors stopped short of determining the intensity of the ancient fields and ascertaining the type of remanence, because the British Museum did not allow heating bulk samples to the minimum of $400^{\circ} \mathrm{C}$ intended in order to induce an artificial TRM.

Even though estimated grain temperatures at accretion of carbonaccous chondrite materials are in the range $300^{\circ} \mathrm{K}$ to $450^{\circ} \mathrm{K}$ (Anders, 1971a), the authors heated powder samples of Orgueil up to 600 to $800^{\circ} \mathrm{C}$, risking to incur drastic chemical changes and thus to irreversibly blur the fossil field record. Nor could they have discriminated, based solely on the stability of NRM to AF demagnetization, between a CRM and a TRM (Banerjee, 1970), though the mode of acquisition of the NRM is as revealing of the physical environment as the paleointensity itself.

The several expcriments suggested below could insure the retrieval of precious information on paleoficlds; they are based on recent techniques developed in rock magnetism, which do not run the risk of irreversible alterations.

\section{First Suggested Experiment}

First, in order to determine the intensity of ambient ficlds at condensation, one could exploit the "memory effect" exhibited by magnetic matcrials such as magnetite, hematite, nickel and cobalt (Ozima et al., 1964; Kobayashi and Fuller, 1968; Nagata et al., 1961). When thermally cycled through the so-called isotropic point $T_{K}$ of minimum magnetocrystalline anisotropy, after demagnetization, a remarkable recovery of the initial NRM, within a fraction of its initial value, is observed. For magnetite, $T_{K}=-145^{\circ} \mathrm{C}$, so that cooling from rather than heating above, room temperature through $T_{K}$, in known fields, may yield within a fraction the desired paleointensity. The "memory" of the initial ficlds is associated with the hardest fraction of grains, with high microcoercivities. Appreciable soft remanence can be acquired without "memory" loss, being erased after a single cooling cycle in field-free space. Nor does repeated thermal cycling change the stability of "memory" to ac field demagnetization. The amplitude of the recovered fraction of NRM after the first cycle may also reveal its mode of acquisition: low field TRM's $(H \lesssim 2$ Oe) have the highest rate of recovery of various artificial IRM's and TRM's, and the lowest relative amplitude loss after several coolingheating cycles (Nagata et al., 1961).

\section{Second Suggested Experiment}

Since the size distribution of magnetite grains in Orgueil had been studied (Kerridge, 1970) and found to peak in the submicron range for clustered grains, but have a lower cutoff at $\sim 5 \mu$ for single grains, it could be verified whether the large magnetic grains can exhibit single domain behavior, as suggested by the finding that physical sizes of 0.5 to $50 \mu$ for magnetite grains in a natural basalt corresponded to effective sizes of 0.03 to $0.08 \mu$ (Dunlop and West, 1969). This could be achieved by combining AF demagnetization with low-temperature cycling (Merrill, 1970). As the former affects remanence of a given coercivity regardless of its carricrs, but the latter affects mainly multi-domain grains, the relative intensities of NRM components residing in each grain size-fraction could be appraised. This would reveal whether useful stable remanence is carried by large, multi-domain grains, and would be of great significance in qualifying the magnetically useful grain fraction in most chondrites. For example, 
although kamacite ( $\mathrm{Ni} / \mathrm{Fe}$ ) grains in chondrites are generally $<50 \mu$, they may reach $\mathrm{mm}$ sizes, as found in the Renazzo (carbonaceous type II) meteorite (Wood, 1967).

\section{Third Suggested Experiment}

It is important to ascertain the reliability of paleointensity estimates for chondrites, which are based on the assumption that the entire NRM is a simple TRM (Stacey et al., 1961). For carbonaceous chondrites in particular, some questions of possible importance are: If a secondary CRM was acquired upon the oxidation of small $(<10 \mu)$ $\mathrm{Ni} / \mathrm{Fe}$ grains as they cooled into the range $T \lesssim 450^{\circ} \mathrm{K}$ where the oxide is stable (Wood, 1967 ; Anders, 1971a), would the original information have been lost? And if a primary CRM was established upon growth of magnetite plaques and spherules directly from a vapor phase (Arrhenius and Alfvén, 1971), and compounded into (P) TCRM's subsequently, would the components be resolvable? Significant recent work (Kellogg et al., 1970; Marshall and Cox, 1971) investigating this aspect, showed that, as long as oxidation occurs during the initial cooling of the nebular material, both the original (P)TRM (of the $\mathrm{Ni} / \mathrm{Fe}$ grains) and the TCRM (acquired by further cooling after oxidation of $\mathrm{Ni} / \mathrm{Fe}$ into magnetite) are proportional to the ambient field, with the same proportionality constant. In general, the proportionality TRM $\propto H$ holds in low ( $H \lesssim 2$ Oe) fields (Everitt, 1961), and will hold for (P) TRM's and (P) TCRM's.

But if the NRM, prior to an oxidation of $\mathrm{Ni} / \mathrm{Fe}$ grains, was not a simple TRM as was assumed for meteorites, the presence of an earlier CRM, (due to recrystallization, diffusional phase changes, etc.) superposed on the TRM could be detected. The procedure involves comparing the spectra of blocking temperatures and microcoercivity of the NRM with those of an artificial TRM (Schwartz, 1969; Schwartz and Symons, 1970), and requiring that the plot of NRM vs TRM after partial thermal and AF demagnetizations, be linear and intercept the origin. If the reliability criteria are not met, the estimate for paleointensity based on laboratory TRM must be rejected. Thus, before estimated values of 0.15 to 0.9 Oe for the ancient field in which chondrites acquired their NRM
(Stacey et al., 1961); or of 0.15 Oe for stony, but 0.6 Oe for iron meteorites in a "planetary" body (Guskova and Pochtarev, 1967, 1969) as TRM are to be accepted, they must fulfill the reliability criteria formulated in Schwartz (1969).

\section{Fourth Suggested Experiment}

A procedure was developed (Doell and Smith, 1969) to improve the linearity of NRM vs induced TRM, which is indicative of the reliability of paleofield intensity derived (Schwartz, 1969). It involves the use of AF and thermal "cleaning" in tandem. For example, using low AF field demagnetization, prior to thermomagnetic analysis for carbonaceous chondrites, will erase low temperature PTRM's (possibly, acquired by postoxidation cooling of the magnetite grains) which are known (Everitt, 1961) to reside in a low coercivity grain fraction.

\section{Fifth Suggested Experiment}

Finally, a method for directly determining the effective size distribution of magnetic grains was described by Dunlop and West (1969). This involves analyzing experimental AF demagnetization curves for suites of PTRM's induced over consecutive, narrow temperature intervals. It yields the same information as the second experiment above, though more laborious, but is applicable to any type of magnetic grains. If undertaken for chondrites and iron meteorites, this procedure could indicate whether indeed they behave as assemblies of high coercivity single- or multi-domain grains and whether the general theoretical models proposed above (Sec. $3)$, apply.

\section{Sixth Suggested Experiment}

In order to confirm the conclusion of several authors (Stacey et al., 1961; Weaving, 1962), that the anisotropic susceptibility of chondrites is due to a general alignment of elongated metal grains, the particles size and elongation spectrum could be simply determined by ferromagnetic resonance techniques (Brown, 1960). The resonance frequency for iron oxide powders is in the microwave region, and is a function of the shape de- 
magnetization factor $\left(N_{b}-N_{a}\right)$, indicative of the elongation $(b / a)$ of ellipsoidai grains. A spectrum of resonant frequencies may yield directly the relative volume fractions of grains of a given elongation.

\section{Other Suggested Experiments}

More narrowly directed experiments, able to confirm or disprove certain aspects of meteoritic genesis, could also be conceived. For example:

(a) The suggestion (Whipple, 1966; Cameron, 1966) that chondrules formed in electrical ("lightning") discharges, from the remelting of the dust found in the matrix of chondrites (Wood, 1967), could be verified as follows. It is known that, where struck by lightning, terrestrial rocks acquire a very large sccondary IRM, which constitutes magnetic "noise" (Irving, 1964). The presence of such a large, but "soft" IRM component in the NRM of individual chondrules, could be ascertained simply by comparing the stability type of the NRM in AF demagnetization to that of artificial TRM's and IRM's. Chondrules of diverse types and metal content, such as those found in the carbonaccous type II chondrite Renazzo, should exhibit a common "soft"-type component, when compared to the NRM of the fine grained unaltered matrix.

Similarly, if the class C2 of carbonaceous chondrites experienced lower peak temperatures than C3 and C4, as proposed (Anders, 1971a), an increasingly prominent soft, IRM component should be found in the bulk NRM. This was perhaps already seen (Stacey et al., 1961) for Mokoia (recrystallized type III), where only an unstable NRM was found, crased upon heating to only $\sim 200^{\circ} \mathrm{C}$. It is also interesting that, for the Brewster ordinary chondrite, the NRM was seen to symmetrically increase from center to the outcr surface by a factor of $\sim 60$, and change its stability type from TRM at center to IRM at edges. If it is an IRM, the high remanence $\left(\sim 3 \times 10^{-1} \mathrm{cmu} / \mathrm{g}\right)$, implies exposure to ficlds as high as $450 \mathrm{Oc}$ (Weaving, 1962), perhaps experienced during the meteorite fall through the atmosphere, across electrical discharge fields.

(b) The magnetic propertics could be used to validate or invalidate the case for cogenetic groups of meteorites. For instance, it should be determined whether the hypersthene chondrites (which are often presumed to derive from a single parent body shattered in a collision with the parent of Ga-Ge group III irons, Jain and Lipschutz, 1969) have similar remanence. It is known that shock (Hargraves and Perkins, 1969) or stress (Stott and Stacey, 1960; Kern, 1961a, b, c) only decreases the intensity of the NRM by affecting its least stable carriers, so that the original information is still recoverable from shocked meteorites. For example, Farmington, a "shocked," apparently severely reheated chondrite (Wood, 1967) had an NRM less stable under thermal demagnetization (disappearing at $500^{\circ} \mathrm{C}$ ) than an artificial TRM. This implies that no reheating above $500^{\circ} \mathrm{C}$ occurred since the event which caused the shock degassing of Farmington, and that the NRM must be either a (P)TRM acquired upon cooling below $500^{\circ} \mathrm{C}$, or a CTRM if the shock event eaused the characteristic "light-dark" phases and veins. Indeed, to account for the large ( $\sim 70$ percent) "soft" component of chondritic NRM (demagnetized in $H_{A F} \sim 5$ to $10 \mathrm{Oe}$ or at $250^{\circ} \mathrm{C}$ ), Guskova (1963) suggested that it may have been acquired anhysteretically at the breakup of the parent body. In that case, only the hard component of NRM, surviving in $H_{A F} \sim 300 \mathrm{Oc}$, contains the information on the parent body environment.

(c) If the iron meteorites in $\mathrm{Ga}-\mathrm{Ge}$ groups IIIa and IIIb do derive from different "raisins" (Levin, 1969) in the same parent body $(R \sim 200$ $\mathrm{km})$, the former being nearer to the surface as indicated by cooling rates data (Goldstein, 1969) $\left(\gtrsim 5^{\circ} \mathrm{C} / 10^{6} \mathrm{yr}\right.$ for IIIa, $<2^{\circ} \mathrm{C} / 10^{6} \mathrm{yr}$ for IIIb), the assumption that thoir NRM is a TRM acquired in a dipole field of a planetary parent body (Pochtarev, 1967) would allow the dipole moment of the parent body $\left(\mathrm{a} \sim H R^{3}\right)$ to be determined from a comparison of the relative remanence of groups IIIa $\left(M_{n} \sim 0.06 \mathrm{cgsm}\right.$, $\chi \sim 1.6 \mathrm{cgsm})$ and IIIb $\left(M_{n} \sim 0.07 \mathrm{cgsm}, \chi \sim 1.7\right.$ cgsm) (Guskova and Pochtarev, 1969).

The planetary origin interpretation of NRM could be ruled out if a consistent field estimate cannot be arrived at by comparing, say, the NRM of chondrites (for which cooling rates, depth of burial and size of parent body were estimated and of pallasites and mesosiderites, for which similar data exist (Wood, 1967; Sonett, 1971; Buseck 
and Goldstein, 1964; Powell, 1969; Fricker et al., 1970).

(d) A laboratory determination of the temperature interval through which various meteorites must have cooled in order to acquire their NRM as $(P)$ TRM in the ficld $(<1$ Oe) in their parent body, could help determine which among the calculated cooling curves (Wood, 1967; Sonett, 1971 ; Fricker et al., 1970) is best. It would thus be possible to select a self-consistent model for the origin of meteorites, which integrates magnetic remanence data with accretion temperatures, cooling histories, chemistry and petrology.

\section{ACKNOWLEDGMENT}

The author is much indebted to $G$. Arrhenius, who originally suggested this topic for investigation, for many helpful discussions. This work has been supported by NASA NGL 05-009-002.

\section{REFERENCES}

Alfven, H., 1954. On the Origin of the Solar System, Oxford Univ. Press, London.

Alfven, H., and Arrhentus, G., 1970. Structure and evolutionary history of the solar system, Astrophys. Space Sci., 1, 186-271; 2, 282-312.

Anders, E., 1971 a. Meteorites and the enrly solar system, Annual Rev. Astron. Astrophys., 9, 1-34.

- $1971 \mathrm{~b}$. Interrelations of meteorites, asteroids and comets, in Physical Studies of Minor Planets, edited by T. Gehrels, NASA SP-267, Supt. of Documents, U.S. Govt. Printing Office, Washington, 429-446,

Arrheniv : G., AND Alfven, H., 1971. Fractionation and condensation in space, Earth Planet. Sci. Lett., 10, 253-267.

Banerjee, S. K., 1970. Rockmagnetism today, J. Appl. Phys., 41, 966-973.

BanerJee, S. K., ANd Harghaves, R. B., 1971. Natural remanent magnetization of carbonaceous chondrites, Earth Planet. Sci. Lett., 10, 392-396.

Blander, M., and Abdel-Gawad, M., 1969. The origin of meteorites and the constrained equilibrium condensation theory, Geochim. Cosmochim. Acta, 33, 701-716.

Blander, M., And Katz, J. L., 1967. Condensation of primordial dust, Geochim. Cosmochim. Acta, 31, $1025-1034$

Bozorth, R. M., 1951. Ferromagnetism, Van Nostrand, New York.

Brown, W. F., Jr., 1960. Single domain particles: New uses of old theorems, Amer. J. Phys., 28, $542-551$.

Buseck, P. R., ANd Goldstern, J. I., 1964. Pallasitic meteorites: Implications regarding the deep structure of asteroids, Science, 159, 300-302.

Cameron, A. G. W., 1963. Contraction of the Sun toward the main sequence, in Origin of the Solar System, edited by R. Jastrow and A. G. W. Cameron, Academic Press, New York, 55-61.

-, 1966. The accumulation of chondritic material, Earth Planel. Sci. Lett., 1, 93-96.

- 1969. Physical conditions in the primitive solar nebula, in Meteorite Research, edited by P. M. Millman, D. Reidel Publ. Co., Dordrecht, Holland, 7-15.

,- 1973 . The carly evolution of the solar system, this volume.

Chatelain, A., Kline, D., Kolopus, J. L., and Weeks, R. A., 1970. Electron and nuclear magnetic resonance of three chondrite meteorites, J. Geophys. Res., 75, 5681-5692.

Doell, R. R., Gromme, C. S., Thorpe, A. N., And Senftle, F. E., 1970. Magnetic studics of Apollo 11 lunar samples. Proc. A pollo 11 Lunar Science Conf., Geochim. Cosmochim. Acta, Suppl. 1, 2097-2102.

Doell, R. R., AND Smith, P. J., 1969. On the use of magnetic cleaning in paleointensity studies, J. Geomagn. Geoelec., 21, 579-594.

Donn, B., And SeArs, G. W., 1963. Planets and comets: Role of crystal growth in their formation, Science, 140, 1208-1211.

Dunlop, D. J., AND WEst, G. F., 1969. An experimental evaluation of single domain theories, Rev. Geophys., 7, 709-757.

Fberhardt, T. P., Geiss, J., and Grögler, N., 1965. Further evidence on the origin of trapped gases in the meteorite Khor Temiki, J. Geophys. Res., 70, 4375-4378.

Evans, M. F, and Wayman, M. L., 1971. An investigation of small magnetic particles by means of electron microscopy, Earth Planet. Sci. Lett., 9, 365-370.

Everitt, C. W. F., 1961. Thermoremanent magnetization. I. Experiments on single domain grains, Phil. Mag., 6, 713-726.

Fricker, P. F., Goldstein, J. I., ANd Scmmers, A. I., 1970. Cooling rates and thermal histories of iron and stony-iron metcorites, Geochim. Cosmochim. Acta, 34, 475-491. 
Gillett, F. C., Stein, W. A., and Solomon, P. M., 1970. The spectrum of VY Canis Majoris from 2.9 to 14 microns, Astrophys. J., 160, L173-L176.

Gruman, R. C., 1969. On the composition of circumstellar grains, Astrophys. J., 155, L185-L187.

Goldstein, J. I., 1969. The classification of iron meteorites, in Meleorite Research, edited by P. M. Millman, D. Reidel Publ. Co., Dordrecht, Holland, 721-737.

Green, H. W., Radcliffe, S. V., Awd Hever, A. H., 1971. Allende meteorite: A high-voltage electron petrographic study, Science, 172, 936-939.

Greenberg, J. M., 1967. Small particles in space, in The Zodiacal Light and the Interplanetary Medium, edited by J. L. Weinberg, NASA SP-150, Supt. of Documents, U.S. Govt. Printing Office, Washington, 215-223.

- 1968. Interstellar grains, in Stars and Stellar Systems, vol. VII, edited by B. M. Middlehurst. and G. P. Kuiper, Univ. Chicago Press, 221-364.

-1970 . Models of the zodiacal light, Space Research $X, 225-232$.

Guskova, E. G., 1963. Investigation of natural remanent magnetization of stony meteorites, Geomagnetizm i Aeronomiya, 3, 308-312.

Guskova, E. G., ANd Pochtarev, V. I., 1967. Magnetic fields in space according to a study of the magnetic properties of meteorites, Geomagnetizm $i$ Aeronomiya, 7, 310-316 (Geomagn. and Aeronom., 7, 245-250).

Goskova, E. G., and Pochtarev, V. I., 1969. Magnetic properties of meteorites of the Soviet collection (in Russian), in Meteorite Research, edited by P. M. Millman, D. Reidel Publ. Co., Dordrecht, Holland, 633-637.

Hackwell, J. A., Geintz, R. D., AND Woolf, N. J., 1970. Interstellar silicate absorption bands, Nature, 227, 822-823.

HaIGH, G., 1958. The process of magnetization by chemical change, Phil. Mag., 3, 267-286.

Hargraves, R. B., AND Perkins, W. F., 1969. Investigations of the effect of shock on natural remanent magnetism, J. Geophys. Res., 74, 2576-2589.

Harper, D. A., aNd Low, F. J., 1971. Far-infrared emission from H II regions, Astrophys. J., 165, L9-L13.

Harris, P. G., AND Tozer, D. C., 1967. Fractionation of iron in the solar system, Nature, 215, 1449-1451.

Herbig, G. H., 1970. VY Canis Majoris II. Interpretation of the energy distribution, Astrophys. $J$, 162, 557-570.

HoYLE, F., 1963. Formation of the planets, in Origin of the Solar System, edited by R. Jastrow and A. G. W. Cameron, Academic Press, New York, 63-71.

Hoyle, F., and Wickramasinghe, N. C., 1968. Condensation of the planets, Nalure, 217, 415418.

Irving, E., 1964. Paleomagnetism and Its Application to Geological and Geophysical Problems, J. Wiley and Sons, New York.

JAIN, A. V., AND LIPSCHUTz, M. E., 1969. Shock histories of hexahedrites and Ga-Ge Group III octahedrites, in Meteorite Research, edited by P. M. Millman, D. Reidel Publ. Co., Dordrecht, Holland, 826-837.

JEFFERY, P. M., AND ANDERs, E., 1970. Origin of primordial noble gases in separated meteoritic minerals, I, Geochim. Cosmochim. Acta, 34, 1175-1198.

JokipIr, J. R., 1964. The distribution of gases in the protoplanetary nebula, Icarus, 3, 248-252.

Jones, R. V., AND SpItzer, L., JR., 1967. Magnetic alignment of interstellar grains, Astrophys. J., 147, 943-964.

Kellogg, K., Larson, E. E., AND Watson, D. E., 1970. Thermochemical remanent magnetization and thermal remanent magnetization: Comparison in a basalt, Science, 170, 628-630.

KERN, J. W., 1961a. Effects of moderate stresses on directions of thermoremanent magnetization, $J$. Geophys. Res., 66, 3801-3805.

_, $1961 \mathrm{~b}$. The effect of stress on susceptibility and magnetization of a partially magnetized multidomain system, J. Geophys. Res., 66, 3807-3816.

_ 1961c. Stress stability of remanent magnetization, J. Geophys. Res., 66, 3817-3820.

KerRidge, J. F., 1967. The mineralogy and genesis of the carbonaceous meteorites, in Mantles of the Earth and Terrestrial Planets, edited by S. K. Runcorn, Interscience, London, 54-56.

,- 1970 . Some observations on the nature of magnetite in the Orgucil meteorite, Earth Planet. Sci. Lett., 9, 299-306.

Kimoto, K., KamiYa, Y., Nonoyama, M, and UYeda, R., 1963. An electron microscope study of fine metal particles prepared by evaporation in argon gas at low pressure, Japan. J. Appl. Phys., 2, 702-713. 
KIMOTo, K., AND Nishid, I., 1967. An electron microscope and electron diffraction study of fine smoke particles prepared by evaporation in argon gas at low pressures (II), Japan. J. Appl. Phys., 6, 1047-1059.

KNELler, F., 1969. Fine particle theory, in Magnetism and Metallurgy, vol. 1, edited by A. E. Berkowitz and E. Kneller, Academic Press, London, 366-464.

Koвау Ashi, K., 1959. Chemical remanent magnetization of ferromagnetic minerals and its application to rock magnetism, $J$. Geomag. Geoelec., 10, 99-117.

Kobayashi, K., and Fuller, M., 1968. Stable remanence and memory of multi-domain materials, with special reference to magnetite, Phil. Mag., 18, 601-624.

Krishna Swamy, K. S., ANd DONn, B., 1968. An analysis of the infrared continuum of comets, Astrophys. $J$., 153, 291-300.

KuHr, L. V., 1964. Mass loss from T Tauri stars, Astrophys. J., 140, 1409-1433.

LAI, D., AND RAJAN, R. S., 1969. Observations on space irradiation of individual crystals of gas-rich meteorites, Nature, 223, 269-271.

LARTMER, J. W., 1970. Chemical fractionation in meteorites III. Major element fractionations in chondrites, Geochim. Cosmochim. Acta, 34, 367-387.

Larimer, J. W., AND Anders, F., 1967. Chemical fractionation in meteorites-II. Abundance patterns and their interpretation, Geochim. Cosmochim. Acta, 31, 1239-1270.

LeftVRe, J., 1970. An experimental study of the dust of iron, carbon, silicon carbide and silica, Astron. Astrophys., 5, 37-44.

Lennert, B., 1970. On the conditions for cosmic grain formation, Cosmic Electrodynamics, 1, 218-232.

LEvin, B. Ju., 1969. Origin of meteorites and planetary cosmogony, in Meteorite Research, edited by P. M. Millman, D. Reidel Publ. Co., Dordrecht, Holland, 16-30.

IIILLE, W., 1960. The nature of the grains in the tails of the comets 1956h and 1957d, Astrophys. $J$., 132, 867-882.

Lord, H. C., 1969. Possible solar primordial hydrogen in the Pesyanoe meteorite, Earth Planet. Sci. Lell., 6, 332-334.

Low, F. J., Johnson, H. L., Kleinmann, D. E., Latham, A. S., and Geisel, S. L., 1970. Photometric and spectroscopic observations of infrared stars, Astrophys. $J ., 160,531-543$.

Low, F. J., AND Sмiтh, B. J., 1966. Infrared observations of a pre-planetary system, Nature, 212, 675-676.

MaAs, R. W., Ney, E. P., and Woolf, N. J., 1970. The 10 $\mu$ emission peak of comet Bennett 1969i, Astrophys. J., 160, L101-L104.

MacQuefn, R. M., 1968. Infrared obscrvations of the outer solar corona, Astrophys. J., 154, 1059-1076.

Marshald, M., AND Cox, A., 1971. Fffect of oxidation on the natural remanent magnetization of titano-magnetite in suboceanic basalt, Nature, 230, 28-31.

Madrain, M. Ch., 1901. Propriétés des dépots électrolytiques de fer obtenus dans un champ magnétique, $J$. Phys. Radium, 10, 123-135.

McCord, T. E., Adams, J. B., And Johnson, T. V., 1970. Asteroid Vesta: Spectral reflectivity and compositional implications, Science, 168, 1445-1447.

Merrilt, R. T., 1970. Low temperature treatments of magnetite and magnetite-bearing rocks, J. Geophys. Res., 75, 3343-3349.

MeYer, CH., JR., 1971. An expcrimental approach to circumstellar condensation, Geochim. Cosmochim. Acta, 35, 551-566.

Nagata, T., Ishikawa, Y., Kinoshita, H., Kono, M., Syono, Y., and Fisher, R. M., 1970. Magnetic properties of lunar crystalline rock and fines, Science, 167, 703-704.

Nagata, T., Yama-AI, M., ANd Akimoto, S., 1961. Memory of initial remanent magnetization and number of repeating heat-treatments in low-temperature behavior of haematite, Nature, $190,620-621$.

$O_{\mathrm{PIK}}, \mathrm{F} . \mathrm{J} ., 1968$. The cometary origin of meteorites, Irish Astron. J., 8, 185-208.

Ozima, M., Ozima, M., and Akimoto, S., 1964. Low temperature characteristics of remanent magnetization of magnetite-self-reversal and recovery phenomena of remanent magnetization, J. Geomagn. Geoelec., 16, 165-177.

Pellas, P., Poupenu, G., Lorin, J. C., Reeves, H., and Audouze, J., 1969. Primitive low-energy particle irradiation of meteoritic crystals, Nature, 223, 272-275.

Pochtarev, V. I., 1967. Magnetic field of planets according to a study of the magnetic properties of meteorites, Geomagnetizm $i$ Aeronomiya, 7, 745-747 (Geomagn. and Aeronom., 7, 609-610). 
Pochtarev, V. I., and Guskova, E. G., 1962. The magnetic properties of meteorites, Geomagnetizm $i$ Aeronomiya, 2, 749-758 (Geomagn. and Aeronom., 2, 626-634).

Powels, B. N., 1969. Petrology and chemistry on mesosiderites. I. Texture and composition of nickel iron, Geochim. Cosmochim. Acta, 33, 789-810.

Purcklt, E. M., 1969. On the alignment of interstellar dust, Physica, 41, 100-127.

Schwartz, E. J., 1969. A discussion of thermal and alternating field demagnetization methods in the estimation of palcomagnetic ficld intensities, J. Geomagn. Geoelec., 21, 669-677.

Schwartz, F. J., and Symons, D. T. A., 1970. Paleomagnetic ficld intensity during cooling of the Sudbury Irruptive 1700 my ago, J. Geophys. Res., 75, 6631-6640.

Schwartz, K, and Schubert, G., 1969. The early despinning of the Sun, Astrophys. Space Sci., $5,444-447$.

Senftle, F. E., Thorpe, A. N., And Lewis, R. R, 1964. Magnetic properties of Ni-Fe spherules in tektites from Isabela, Philippine Islands, $J$. Geophys. Res., 69, 317-324.

SonetT, C. P., 1971. The relationship of meteoritic parent body thermal histories and electromagnetic heating by a pre-main sequence T-Tauri sun, in Physical Studies of Minor Planets, edited by 'T. Gehrels, NASA SP-267, Supt. of Documents, U.S. Govt. Printing Office, Washington, 239-246.

SonetT, C. P., Colburn, D. S., Schwartz, K., and Keil, K., 1970. The melting of asteroidalsized bodies by unipolar dynamo induction from a primordial T-Tauri sun, Astrophys. Space Sci, $7,446-488$.

Spitzer, L., Jr., 1963. Star formation, in Origin of the Solar System, edited by R. Jastrow and A. G. W. Cameron, Academic Press, New York, 39-53.

Spitzer, L., JR., AND TUkEY, J. W., 1949. Interstellar polarization, galactic magnetic fields and ferromagnetism, Science, 109, 461-462.

Stacey, F. D., 1960a. Magnetic anisotropy of igneous rocks, $J$. Geophys. Res., 65, 2429-2442.

- 1960b. Magnetic anisotropy of dispersed powders, Australian J. Phys., 13, 196-201.

Stacey, F. D., and Lovering, J. F., 1959. Natural magnetic moments of two chondritic meteorites, Nalure, 183, 529-530.

Stacey, F. D., Lovering, J. F., and Parry, L. G., 1961. Thermomagnetic properties, natural magnetic moments and magnetic anisotropies of some chondritic meteorites, $J$. Geophys. Res., 66, 1523-1534.

StotT, P. M., AND StaceY, F. D., 1960. Magnetostriction and paleomagnetism of igneous rocks, J. Geophys. Res., 65, $2419-2424$.

Strangway, D. W., Larson, E. E., and Goldstein, M., 1968. A possible cause of high magnetic stability in volcanic rocks, $J$. Geophys. Res., 73, 3787-3795.

Strangway, D. W., Larson, E. F., ANd Pearce, G. W., 1970. Magnetic properties of lunar samples, Science, 167, 691-693.

Strom, K. M., Strom, S. E., And Yost, J., 1971. Cireumstellar shells in the young cluster NGC 2264, Astrophys. J., 165, 479-488.

Sutherland, D. N., 1970. Chain formation of fine particle aggregates, Nalure, 226, 1241-1242.

Tanaka, T., and Tamagawa, N., 1967. Magnetic properties of Fe-Co alloy fine particles, Japan. J. Appl. Phys., 6, 1096-1100.

Thorpe, A. N., And SenfTLe, F. E., 1964. Submicroscopic spherules and color of tektites, Geochim. Cosmochim. Acta, 28, 981-994.

VEhHOOGEN, J., 1959. The origin of thermoremanent magnetization, J. Geophys. Res., 64, 24412449.

Weaving, B., 1961. Magnetic anisotropy in chondritic meteorites, Geochim. Cosmochim. Acta, 26, 451-455.

- 1962. The magnetic properties of the Brewster meteorite, Geophys. J., 7, 203-211.

Wethfrill, G. W., 1971. Cometary vs asteroidal origin of chondritic meteorites, in Physical Studies of Minor Planets, edited by T. Gehrels, NASA SP-267, Supt. of Documents, U.S. Govt. Printing Office, Washington, 447-460.

Whipple, F. L., 1966. A suggestion as to the origin of chondrules, Science, 153, 54-56.

Wickramasinghe, N. C., AND NANDY, K., 1970. Interstellar extinction by graphite, iron and silicate grains, Nature, 227, 51-53.

Wood, J. A., 1962. Chondrules and the origin of terrestrial planets, Nature, 194, 127-130.

, 1967. Chondrites: Their metallic minerals, thermal histories and parent planets, Icarus, 6, 1-49.

Woolf, N. J., Strin, W. A., and Stritrmatter, P. A., 1970. Infrared emission from Be stars, Astron. Astrophys., 9, 252-258. 
